\title{
Patterns of strategic voting in run-off elections ${ }^{1}$
}

\author{
KARINE VAN DER STRAETEN \\ Toulouse School of Economics, CNRS \\ JEAN-FRANÇOIS LASLIER \\ Paris School of Economics, CNRS
}

ANDRÉ BLAIS

Université de Montréal, Département de science politique

23 décembre 2014

\begin{abstract}
$\underline{\text { Abstract }}$
The paper studies individual-level strategic voting in run-off elections and makes two contributions. On the theoretical side, we propose a typology of the strategic situations a voter can face and of the kind of reasoning that the rational voter should perform in such situations. On the empirical side, we conduct laboratory experiments and show that voters follow such reasoning when it is simple enough, particularly when there is a serious possibility that a candidate reaches the absolute majority threshold in the first round. But more complex conditional reasonings based on 'backward induction' are seldom followed.
\end{abstract}

\footnotetext{
1 The authors thank the Social Sciences and Humanities Research Council of Canada (Project 'Making Electoral Democracy Work',) and the Center for the Study of Democratic Citizenship for their financial support, and the laboratories of experimental economics in Paris (LEEP) and in Montréal (CIRANO). Thanks also to Damien Bol for his useful comments.
} 


\section{Introduction}

In political science, the notion of strategic voting commonly refers to the idea that a voter does not vote for her preferred candidate, but instead votes for another one with some instrumental goal in mind, specifically the outcome of the election (Blais et al. 2001). In practice, the most common instance of strategic voting is the desertion of non-viable candidates: I refrain from voting for a candidate whom I like but who has no chance of winning, because voting for this candidate does not have desirable consequences compared with voting for a more serious, viable, though less preferred one.

In the rational decision making and game theory literature (e.g. Myerson and Weber, 1993), the definition of strategic voting is slightly different; it refers to the idea that the voter's choice results from the maximization of a well defined utility function, this utility depending solely on the result of the election (who is elected). The difference with the previous definition is essentially semantic: "strategic" in the first sense is a synonym for "strategic and non-sincere", where "sincere voting" means voting for my preferred candidate.

In what follows, we stick to these definitions and consider purely instrumental voters, who only care about the identity of the elected candidate, leaving aside other motives such as signalling their political stands or following some norms. We use "strategic" in the rational decision making sense, but we are chiefly interested, in the experimental part of the paper, in "strategic and non sincere" votes.

The idea that voters cast their votes strategically in order to get the best possible outcome has been explored in theory (Cox, 1997), and its practical importance bas been well documented, using different empirical methods: see for example Karp et al. 2002, Blais 2003, Gschwend 2007a, 
or Merolla and Stephenson 2007 for studies based on electoral surveys; Forsythe et al. 1993, Kube and Puppe 2009, Morton and Rietz 2006, Rietz 2008, or Van der Straeten et al. 2010 for laboratory experiments; and Kawai and Watanabe 2012, or Spenkuch 2014 for studies based on aggregate vote counts.

Our contribution in this paper is to study strategic voting in run-off elections. Our motivation for studying the run-off rule is twofold. The first motivation is its practical relevance throughout the world. Although most of the literature on strategic voting, theoretical as well as empirical, is concerned with first past the post (henceworth FPTP) elections, two-round run-off elections are extremely common throughout the world. This system is the most common rule for presidential elections: out of 103 countries with direct presidential elections, 82 have a run-off system. ${ }^{2}$

The second motivation is that strategic reasoning in run-off elections is richer and more complex than in FPTP elections, as noticed by Cox 1997 and as will be detailed below. The simplest variant of the run-off rule, the one that we will study, is as follows. On the first round, the voter casts a vote for one candidate. If one candidate obtains more than $50 \%$ of the votes, he is elected. If not, there is a second round between the two candidates who obtained the highest numbers of votes in the first round. In this second round, each voter casts one vote for one of the remaining two candidates, and the candidate who then obtains more than $50 \%$ of these votes is elected.

Previous empirical studies have shown that people sometimes vote strategically and sometimes do not. In order to deepen our understanding of voters' behavior, we refine the question and ask: "What kind of rational behavior do people follow, and what kind do they not?" Run-off

\footnotetext{
${ }^{2}$ According to the Institute for Democratic and Electoral Assistance (http://www.idea.int/index.cfm). See Blais et al. 1997 or Golder 2005.
} 
elections offer a wide variety of strategic reasonings and provide an interesting context for raising this question. ${ }^{3}$

The experiments analyzed in the present paper are variations on the experiments presented in Van der Straeten et al, 2010 or Blais et al. 2010. Analyzing these previous experiments, we noticed that the amount of strategic voting was not uniform and seemed to depend on the details of the circumstances: the position of the voter, the past results and the precise structure of the competition among candidates. We replicated the protocol, with some adjustments, in order to try to understand this point in more details.

In the first part of the paper (section 2), we go into the details of what it entails, for a rational voter, to vote strategically under the run-off rule. We distinguish different reasonings under different types of pivot events. It is important to note that we describe patterns of strategic reasoning at the individual level. We do not study the equilibria of a strategic game in which all voters would be perfectly strategic, knowing that the others are as well. (For equilibrium analysis of similar games, see for instance Martinelli 2002, Bouton 2013, Bouton and Gratton 2013) We believe that individuel-level analysis is an important complement to these equilibrium analyses. Indeed, as we will show, all voters are not perfectly strategic. In a world where not all agents are rational, the best actions to undertake may be different from those predicted by equilibrium analysis.

\footnotetext{
${ }^{3}$ For a similar route, although in a quite different context, see Esponda and Vespa (2013). In a voting experiment with private information, they study heterogeneity in cognitive abilities across subjects. They aim at understanding when the strategic model fails to perform well in explaining actual behavior, and the sources of the failure: failure of hypothetical thinking vs. failure of information extraction from other voters' votes. Koriyama and Ozkes (2014) study bounded rationality in voting under imperfect information with a model of hierarchical rationality levels.
} 
Once the typology of all the possible forms of strategic reasoning has been established, we design laboratory experiments to test which kinds of strategic reasoning subjects follow, if any. To stay as close as possible to the theoretical model, we use an abstract framework, in which subjects vote for alternatives, each yielding a different payoff if elected. The design is meant to mimic single-dimensional politics with single-peaked preferences. Using abstract alternatives (letters) and monetary-induced preferences, we aim at being close to the assumptions of the theoretical model, where subjects are assumed to care only about the payoffs associated to the candidate to be elected (and have no expressive motives). The objective is to test whether subjects perform the various types of reasoning which have been identified in the theory. We show that people tend to follow simple types of reasoning but not complicated ones, and we characterize the types of reasoning which are the most likely to be followed.

The paper is organized as follows: Section 2 establishes the typology of strategic voting under the run-off rule, Section 3 describes the experimental protocol, the method for data analysis, and the experimental results. Section 4 provides some robusteness tests for our main findings. Section 5 briefly concludes.

\section{A typology of strategic reasoning in run-off elections}

We assume that voters are only interested in the outcome of the election (who gets elected), and that they have well defined preferences over the set of candidates. Voting is costless.

By strategic behavior we mean that an individual chooses an action (a vote) that maximizes her expected utility given her beliefs about how the other voters are going to vote in the coming election. Her beliefs bear on the distribution of other voters' votes across candidates.

Note that at the second round, if any, the voter has the choice between two candidates, 
therefore voting for one's preferred candidate among the two run-off candidates is a dominant strategy. Let us therefore focus on strategic behavior in the first round. A first-round outcome is either the direct election (on the first-round) of one of the candidates (if he gets more than $50 \%$ of the votes), or a run-off between two candidates. For a voter, in all the events such that the other voters' votes yield the same first-round outcome whoever she votes for, all her actions yield the same payoff. Actions yield different outcomes (the voter is then said to be pivotal) if and only if the other voters' votes are such that (at least) one of following two conditions holds:

- Condition 1: A candidate gets an absolute majority minus one vote.

- Condition 2: No candidate gets an absolute majority, and the vote margin between the candidates receiving the 2 nd and $3 r d$ highest numbers of votes is at most one vote.

We describe the strategic recommendation, first when condition 1 holds, and then when condition 2 holds. ${ }^{4}$ For each type of event, we derive how a voter should vote, if she believes that this event is to happen with probability 1. Our typology is based on the description of the voter's best response given her beliefs about the votes cast by the other voters, when there is no uncertainty about the first-round scores of the candidates. In particular, we will focus in our typology on reasonings yielding a unique best response. In the empirical part of the paper, and in particular in section 3.2, we describe our assumptions about how voters form (noisy) beliefs about those scores.

\footnotetext{
${ }^{4}$ In most cases, the two conditions will not hold together, and by her actions, the voter will only be able to induce at most two different first-round outcomes. Notice that there can be more complex situations, where the voter can induce through her actions three or more possible first-round outcomes. This will be the case for example if conditions 1 and 2 simultaneously hold, or if three (or more) candidates are tied for the first rank (in which case at least three different run-offs are possible). Since our objective is to derive a simple typology, we restrict our attention to events in which the voter's action can only produce two different first-round outcomes.
} 
TYPE 1: "First-round winner" pivot reasoning: When Condition 1 holds $\mathbf{5}^{\mathbf{5}}$, if the voter votes for the candidate who receives an absolute majority minus one vote (call it "the leader"), this candidate is elected at the first round, whereas if the voter votes for any other candidate, there is a run-off between the leader and the candidate ranked second (call it "the main challenger"). ${ }^{6}$ Then, as soon as the voter anticipates that the main challenger can be elected if opposed to the leader at the run-off, the voter should vote for the leader if and only if she prefers the leader to his main challenger. This type of strategic reasoning, when inducing a vote for or against the leader, will be called TYPE 1 reasoning. ${ }^{7}$

Note that this type of reasoning is close to strategic reasoning in FPTP elections (vote for the leader if you like him better than his main challenger).

TYPES 2 to 4: "Second-round composition" pivot reasonings: When Condition 2 holds, the voter is pivotal in deciding the composition of the pair of candidates which are going to be part of the run-off. The voter is now pivotal in deciding which one of the candidates ranked second and

\footnotetext{
${ }^{5}$ In the terminology by Bouton 2013, the voter is said to be "threshold- pivotal".

${ }^{6}$ Our restrictions about the set of events (as noted in Footnote 4) imply that there is only one such candidate, who gets strictly less than the majority minus one vote.

${ }^{7}$ Note that if the voter prefers the main challenger to the leader, she prefers a run-off between the leader and his main challenger to a direct win of the leader. In that case all actions, exept of course voting for the leader, yield the same outcome (the run-off between the leader and the main challenger) and thus the same payoff.. In that case, the voter can, as well, decide to vote for any other condidate. This will not be considered as "Type 1" reasoning since, as explained above, we define our types refereeing to situations which yield unique best responses. Similarly, if it is certain that the leader will defeat the main challenger in case of a runoff, all actions yield the same payoff, and this situation is not considered as Type 1 reasoning either.
} 
third is going to join the leader in the run-off. ${ }^{8}$ The strategic recommendation is to vote for one of these two challengers. We further decompose the type of reasoning that the voter should perform in such pivot events, depending on the relative performance of the two challengers in case of a run-off against the leader.

- If the voter considers that, in case of a run-off, both challengers will be equally strong against the leader (that is, if they both have the same probabilities of winning against the leader in a run-off), then the voter should vote for the candidate she prefers between the two challengers. This type of reasoning will be called TYPE 2 reasoning.

- If the voter considers instead that, in case of a run-off, the two challengers will not be equally strong against the leader, then the real choice for the voter (in terms of final outcome of the election), is between electing the leader and electing the "strong challenger", where we call "strong challenger" this challenger whose probability of defeating the leader is the highest.

In order to determine which challenger she should vote for, the voter should compare the utility she derives from the election of the strong challenger and the utility she derives from the election of the leader. We break the strategic reasoning in that case into two types, depending on the voter's utilities for the leader versus the strong challenger.

- Suppose that the voter prefers the strong challenger to the leader. Then she should vote for this strong challenger. This reasoning will be labelled TYPE 3 reasoning.

- Suppose that the voter prefers the leader to the strong challenger. Then she should vote for the weakest run-off challenger. This reasoning will be labelled TYPE 4 reasoning. It means that the voter votes for the weak challenger, even if she dislikes this candidate,

\footnotetext{
${ }^{8}$ Again, our restrictions about the set of possible first-round outcomes imply that there is only one leader, and only two challengers.
} 
because he is more likely to be defeated by the leader in case of a run-off. This last type is the "push-over" tactics identified by Cox (1997).

Comments on the typology. The above four-item typology is relatively simple, and yet it accounts for the main types of reasoning a voter may have to perform in a run-off election. Clearly some of these reasonings are more intricate than others. The simplest situation is when there is the possibility of a majority winner in the first round (Type 1). In that case the voter just has to determine whether she prefers to provoke a run-off between the leader and his main challenger, or to provoke the election of the former. The more complex reasonings are those in which the voter decides how to vote in the first round on the basis of expectations about what is likely to occur in the second round. In particular, some amount of sophistication is required in cases where the strategic recommendation is to vote for a candidate other than the preferred one because this will increase the probability of the preferred candidate winning in the run-off (Type 4).

\section{Strategic reasoning in the laboratory}

\subsection{Description of the experiment}

We designed a laboratory experiment to test whether subjects, playing the role of voters, follow or not the four types of strategic reasoning identified in the first part of the paper. In particular, we use an abstract setting with monetary-induced preferences, to make sure that subjects are mostly concerned with the outcome of the election (who gets elected) rather than with other possible motives. Besides, we choose a profile of voters' preferences and profiles of candidate positions such that subjects are likely to find themselves in the position to perform the four types of reasoning identified in the theoretical section. 
The protocol is an adaptation from the one used in Van der Straeten et al. (2010). 21 subjects vote among a set of exogenously given candidates. Some elections are held with three candidates, some with five candidates. In some elections the voting rule was two round with a run-off, in other elections it was FPTP. Although in the present paper we only use data from the run-off elections, we nevertheless describe here the full protocol fro the sake of exactness. ${ }^{9}$

Candidates are located on an axis, presented as going from left to right, from position 0 to position 20 . The 21 subjects are randomly assigned a position on this axis, each position being filled by exactly one subject (see below for a more precise description of this assignment). The monetary incentive for a subject is that the elected candidate be as close as possible to her position. Subjects are informed that they will be paid 20 Euros (or Canadian dollars) minus the distance between the elected candidate's position and their own. ${ }^{10}$.

Elections go by sequences of four. During four consecutive elections, the number of candidates, their positions on the axis, as well as the voting rule, are kept constant. After each election, voters are immediately informed of the results, that is which candidate is elected and the number of votes obtained by the various candidates (in both rounds for the elections with run-off). At the beginning of each sequence of four elections, participants are assigned a randomly drawn position on the 0 to 20 axis, which they keep for the whole sequence. There is a total of 21 positions, and each participant has a different position. The participants are informed about the distribution of positions: they know their own position, they know that each possible position is

\footnotetext{
9 The full instructions are available upon request.

${ }^{10}$ During one session, each subject participates in total to 32 elections. The participants are informed from the beginning that one of the 32 elections will be randomly drawn as the "decisive" election, the one which will actually determine payoffs. This is customary in experimental economics. This has the advantage of keeping subjects equally interested in all elections and to avoid insurance effects; see Davis and Holt (1993).
} 
filled exactly once but they do not know by whom. Voting is anonymous and costless.

Each subject participates in eight sequences of four elections, each sequence being chacracterized by the voting rule and the number/positions of the candidates. Table 1 describes the positions of the candidates and the voting rule in the eight sequences. Each cell of the table describes the charcateristics of one of the eight sequences.

\begin{tabular}{|l|l|}
\hline Candidate position $\backslash$ & \\
\hline Structure sI, 3 candidates & $\mathbf{7 , 9 , 1 6}$ \\
\hline Structure sI, 5 candidates & $\mathbf{1 , 4 , 1 1 , 1 3 , 2 0}$ \\
\hline Structure sII, 3 candidates & $\mathbf{5 , 1 2 , 1 7}$ \\
\hline Structure sII, 5 candidates & $\mathbf{0 , 3 , 8 , 1 5 , 2 0}$ \\
\hline
\end{tabular}

Table 1: Positions of the candidates on the $[0,20]$ axis in the eight sequences

There are four sequences with three candidates, four sequences with five candidates, four sequences with FPTP and 4 sequences with the run-off voting rule.. Up to symetries, we basically have two structures of political offer:

- Structure sI: A centrist candidate has a close opponent and a distant one (respective positions 9,7 , and 16).

- Structure sII: A centrist candidate has two distant opponents (respective positions 12, 5 and 17).

Variations are obtained by adding extreme candidates and by using the mirror operation.

At the end of the session subjects are asked, before receiving their money, to fill a small questionnaire. Cooperation and communication among voters are banned. We organized nine such 
sessions: five in Paris in 2009 and four in Montréal in 2010. ${ }^{13}$

Voters vote under different candidate profiles in our experiment. The reasons why we chose those precise candidate positions are explained in the Appendix. We have identified, in theory, four types of strategic reasoning. Our objective is to ascertain whether the subjects follow, or not, each of them. We therefore aimed at designing electoral contexts that were likely to generate all these possible types of reasoning. Because it was difficult to do so with one single profile of candidate positions, we chose to have four different candidate profiles. Note that we use these different profiles as instruments to generate all possible types of reasoning, but that we are not interested in the comparison of the outcomes under these different profiles per se. The next section will show that we have been successful in generating all the possible situations of strategic reasoning, and that the various profiles were indeed needed to reach this goal.

In the baseline experiment, the results of which will be presented in sections 3.2 and 3.3 , sequences had four elections each. In order to further study the influence of time on the performance of the strategic model, we also run a follow-up experiment with sequences of 15 elections each (see section 4.2. for a precise description and results.)

\subsection{Dermining the strategic recommendation and the type of reasoning}

Our objective is to determine, for each voter in each election, the type of reasoning she has to perform, using the typology established in section 2 . Then, for each of these observations, we test whether the voter's actual behavior is consistent with the theoretical prediction or not. In this

\footnotetext{
${ }^{13}$ The candidate positions in structure sII were fine-tuned in the first two sessions: in the first session, the positions were $(0,5,14,18,20)$ and in the second $(0,5,12,18,20)$. We then adopted positions $(0,5,14,17,20)$, which were kept for the remaining sessions. Results are presented pooling all sessions. Treating them separately does not alter the results. Some more sessions we realized in Paris in 2014 to study learning and are presented in section 4.2.
} 
subsection, we explain how we determine, for each voter in each election, the strategic recommendation and the type of reasoning driving to that recommendation. We then show that our experimental design was successful in generating situations calling for all possible types of reasoning.

Assumptions about voters' anticipations. When a voter is to cast her vote, she knows the profile of candidates, the profile of voters, as well as her own position. According to the strategic model, she needs to form some beliefs about what the other voters' votes are going to be. We therefore need to make some assumptions about these beliefs.

Let us first describe our assumptions about her anticipations of the first-round votes. Following the rationality paradigm, we make the assumption of rational perfect anticipations: individual beliefs are correct in the sense that the individual either "knows" the truth, or has probabilistic beliefs which are exact in expectation (no systematic bias). More precisely, if voter $j$ is going to vote for candidate $K$, voter $i$ almost knows this: voter $i$ 's belief is that voter $j$ is going to vote for $K$ with the (high) probability $1-\varepsilon$, and that $j$ will vote for another, randomly chosen candidate, with probability $\varepsilon$. Errors are independent across voters and across elections. As a consequence of this assumption, each voter considers that one event is much more likely than any other event: this event is simply the truth, correctly anticipated. Then the second most likely events are events where one (and exactly one) voter deviates, the third most likely events are events where exactly two voters deviate, etc.

This assumption of perfect anticipations is attractive because it is consistent with the rationality paradigm. In this section, we will stick to this assumption. But one might argue that it is difficult for voters to correctly anticipate the scores of all the candidates. In reality, anticipations seem to be shaped to a great extend by the outcome of previous elections, as found by Gschwend (2007b) or Lago (2008) in observational studies based on aggregate-level statistics and vote 
returns.

In section 4.1., we replicate our main analysis under an alternative assumption of "myopic" anticipations: each voter thinks that the others will behave in the current election just as they did in the previous one. Instead of perfectly anticipating, they do not anticipate at all. As will be seen, the results are essentially the same with this variant.

Another possibility would be to elicit voters' beliefs. This point is studied in Blais et al. 2014 . To elicit beliefs is possible but has some costs. First, eliciting belief in an incentive-compatible way is doable, but it complexifies the protocol, takes time during the sessions, and slows down the whole process. Second, and more important, it incentivates the voter to hold such beliefs, to make them acurate, and thus to use them. But we do not want to dictate the participants how they should come to a decision. For these reasons, we decided this time not to elicit beliefs.

Let us now describe our assumptions about the voter's anticipations of the second round votes. ${ }^{14}$ Indeed, these beliefs are important to determine the optimal first-round vote, as was underlined when establishing the typology of possible reasonings. When anticipating the outcomes of all possible run-offs, voter $i$ believes that with the (very high) probability $1-\varepsilon$, voter $j$ will follow her dominant strategy, that is, vote for the candidate which is closer to $j$ 's position (and randomize in case of indifference), but that with a small error probability $\varepsilon$, voter $j$ will vote for the other candidate. Again, errors are independent across voters, and are independent across elections.

This model of "noisy" anticipations, or "trembled" beliefs, draws on the refinement literature in game theory (Selten 1975; Myerson 1991, Chap. 5). Similar models are standard in voting games (Myerson and Weber 1993, Myerson 2002, Laslier 2009). Under these assumptions,

\footnotetext{
${ }^{14}$ These assumptions about run-off outcomes will be similar in the perfect and myopic models of first-round expectations.
} 
with $\varepsilon$ small enough, when looking for the rational vote to cast, the voter should have the following reasoning. If her vote can make a difference in case no other voter makes a mistake, she should take the action yielding the highest payoff. If her vote makes no difference in case no other voter makes a mistake, or if several actions yield the same highest payoff, then she has to consider second-order events. These will be events where exactly one voter makes a mistake, either at the first round or at the second round. This amounts to allowing transfers of one unit in the candidate scores, either at the first or the second round. If considering second-order events is not conclusive, the voter should turn to third-order events, and so on. ${ }^{15}$

In our analysis, we run these computations for each individual at each election (Mathematica program avalaible upon request). This analysis becomes computationally demanding if we wish to consider events with high orders. For example, with three candidates, restricting attention to the first round, there is only one truth, 40 possibilities for a single mistake ${ }^{16}, 760$ possibilities for two mistakes, 9120 possibilities for three mistakes, etc. Practically, an exhaustive search is not feasible for four mistakes, in particular with five candidates. Notice that the argument that leads to the conclusion "this is the rational vote" becomes weaker and weaker when it requires to go from one order to the next. In that case, the conclusion tends to be based on tiny probabilities, which makes the expected utilities attached to the various actions almost identical. It is therefore reasonable not

\footnotetext{
15 To make a link with the "bounded rationality" literature, note that the models of "trembled anticipations" used for theory following Myerson 2000, or used for individual data analysis in the present paper, can be seen as specific instances of Tversky's theory of choice by sequential elimination: the "aspects" to be sequentially considered by the individual in order to reach a (unique) decision are the events of successive magnitudes. See Tversky 1972, Tversky and Sattah 1979.

16 Denoting by $A, B, C$ the candidates, let $n_{A}, n_{B}, n_{C}$ be the numbers of votes obtained from voters other than voter $i$ (with $\left.n_{A}+n_{B}+n_{C}=20\right)$. What are the possibilities for one mistake? The $n_{A}$ voters voting for $A$ could vote for $B$ or $C$ ( $2 n_{A}$ possibilities), the $n_{B}$ voters voting for $B$ could vote for $A$ or $C$ ( $2 n_{B}$ possibilities), and the $n_{C}$ voters voting for $C$ could vote for $A$ or $B\left(2 n_{C}\right.$ possibilities $)$, which yields a total or $2\left(n_{A}+n_{B}+n_{C}\right)=40$ possibilities.
} 
to rely on conclusions based on too many mistakes. We confine ourselves to three mistakes or less.

Table 2 shows the number of observations in which the strategic recommendation (the rational vote) is uniquely determined with up to three mistakes, and how many mistakes is required to uniquely define this vote. We have nine sessions, with four sequences of four consecutive run-off elections, and 21 voters. We are interested in the first-round behavior of these voters, so that we have a total number of 3,024 observations. In 384 cases, the strategic recommendation is unique even when the other voters make no mistake. Notice that in 540 cases there is no unique strategic recommendation, even considering up to three mistakes.

\begin{tabular}{|c|c|c|c|c|c|}
\hline \multicolumn{4}{|c|}{$\begin{array}{l}\text { Unique recommendation } \\
\text { reached with } 3 \text { errors or less }\end{array}$} & $\begin{array}{c}\text { No unique } \\
\text { recommendation } \\
\text { after } 3 \text { errors }\end{array}$ & Total \\
\hline \multicolumn{4}{|c|}{2,484} & 540 & 3,024 \\
\hline 0 error & 1 error & 2 errors & 3 errors & & \\
\hline 384 & 531 & 822 & 540 & & \\
\hline
\end{tabular}

Table 2: Number of unique strategic recommendations (Perfect anticipations assumption), by number of errors needed to reach a unique recommendation (4-election sessions)

The distribution of the types of reasoning in the data. The next step is, for each of the 2,484 observations with unique strategic prediction, to identify the type of reasoning leading to this recommendation. The computer program that has been written to compute the strategic recommendation is also used to determine, each time a unique recommendation is found, what type of reasoning led to this conclusion.

Table 3 gives the distribution of types by political structure and number of candidates. In the table, we merge together, under the label "undefined", observations where three errors were not 
enough to derive unique predictions (the 540 observations in Table 2) with observations for which the strategic recommendation was indeed unique but where the type was undefined. ${ }^{17}$ One sees in Table 3 that the strategic recommendation is unique, and the type is well-defined, in $204+563+544+529=2,188$ cases. $^{18}$

\begin{tabular}{|c|c|c|}
\hline & Structure sI, 3 candidates & Structure sI, 5 candidates \\
\hline Type 1 & 110 & 76 \\
\hline Type 2 & 268 & 161 \\
\hline Type 3 & 130 & 192 \\
\hline Type 4 & 44 & 134 \\
\hline Type Defined & 552 & 563 \\
\hline Undefined & 204 & 193 \\
\hline Total & 756 & 756 \\
\hline & Structure sII, 3 candidates & Structure sII, 5 candidates \\
\hline Type 1 & 366 & 248 \\
\hline Type 2 & 44 & 54 \\
\hline Type 3 & 121 & 154 \\
\hline Type 4 & 13 & 73 \\
\hline Type Defined & 544 & 529 \\
\hline Undefined & 212 & 756 \\
\hline Total & 756 & \\
\hline
\end{tabular}

Table 3: Distribution of types of reasoning (Perfect anticipations assumption), by structure and number of candidates (4-election sessions)

\footnotetext{
17 Indeed, in some (rare) cases, a recommendation may be of no well-defined type: as noted when defining the types, our typology does not cover events where a voter's action can produce three or more different outcomes (for example, when three candidates are tied for first place).

18 Therefore, among the 2,484 observations for which a unique strategic recommendation was found, 2,188, that is $88 \%$, have a well-defined type.
} 
Note that the selected political structures were successful in placing subjects in situations where they should perform the various types of reasoning which have been identified by the theory, but that no single profile could generate all types in sufficient numbers. This justifies our choice of having voters vote under different candidate profiles. (In the appendix we explain the reasons which led to the choice of these particular profiles.)

One can read in Table 3 that political structure sI generates 186 cases of Type 1 reasoning, 110 under the three-candidate profile, and 76 under the five-candidate profile. Type 1 reasoning is more frequent with three candidates than with five candidates, and more frequent under political structure sII than under political structure sI, as expected when choosing these profiles (see the Appendix more more details). This is also consistent with the numbers presented in Table 4, which shows the percentage of elections where there was a first-round or a second-round winner, by political structure and number of candidates.

\begin{tabular}{|c|c|c|c|c|}
\hline & & $\begin{array}{c}\text { First } \\
\text { round } \\
\text { winner }\end{array}$ & $\begin{array}{l}\text { Run-off } \\
\text { winner }\end{array}$ & Total \\
\hline Structure sI & Centrist winner & 22 & 56 & 78 \\
\hline & Other winner & 8 & 14 & 22 \\
\hline & Total & 31 & 69 & 100 \\
\hline & & & 0 & 0 \\
\hline Structure sI & Centrist winner & 11 & 72 & 83 \\
\hline 5 candidates & Other winner & 0 & 17 & 17 \\
\hline & Total & 11 & 89 & 100 \\
\hline & & & 0 & 0 \\
\hline Structure sII & Centrist winner & 53 & 39 & 92 \\
\hline & Other winner & 8 & 0 & 8 \\
\hline & Total & 61 & 39 & 100 \\
\hline & & & 0 & 0 \\
\hline
\end{tabular}




\begin{tabular}{|l|l|c|c|c|}
\hline $\begin{array}{l}\text { Structure sII } \\
5\end{array}$ candidates & Centrist winner & 36 & 56 & 92 \\
\cline { 2 - 5 } & Other winner & 3 & 6 & 8 \\
\cline { 2 - 5 } & Total & 39 & 61 & 100 \\
\hline
\end{tabular}

Table 4: Percentage of first and second round winners, percentages of victory of the centrist candidate, by political structure and number of candidates (4-election sessions)

We observe in Table 4 that first round winners are more frequent with three candidates (31\% in structure sI and $61 \%$ in structure sII, that is $46 \%$ in total) than with five candidates (11\% in structure sI and $39 \%$ in structure sII, that is $25 \%$ in total). These figures vary with the political structure: a first-round winner is more often observed with structure sII (50\% of the cases) than with structure sI (24\%), which is also consistent with our expectations.

\subsection{Do subjects follow the different types of strategic reasoning?}

With no surprise, it is often the case that the payoff-maximizing action is to vote for the candidate closest to the voter's own position, that is, to vote sincerely. To perform a sharper test of the theory of strategic reasoning, we restrict our attention to the cases where the sincere and strategic recommendations are in conflict Our main goal is to measure the propensity to behave strategically and to see how this varies with the type of strategic reasoning to be performed. We thus restrict our attention to the cases where (i) the strategic recommendation is well-defined and unique, (ii) the type of strategic reasoning is well-defined, (iii) the sincere recommendation is well defined and unique, and (iv) the sincere recommendation differs from the strategic recommendation. We call these situations "strategic dilemmas".

The last column of Table 5 shows, for each type of reasoning, the percentage of dilemmas which are resolved strategically. The number of observations on which this percentage is computed 
is noted below in parentheses.

\begin{tabular}{|c|c|c|c|c|c|}
\hline & Election 1 & Election 2 & Election 3 & Election 4 & Total \\
\hline Type 1 & $\begin{array}{c}31 \% \\
(=12 / 39)\end{array}$ & $\begin{array}{c}49 \% \\
(=37 / 75)\end{array}$ & $\begin{array}{c}62 \% \\
(=58 / 93)\end{array}$ & $\begin{array}{c}62 \% \\
(=48 / 79)\end{array}$ & $\begin{array}{c}\mathbf{5 5 \%} \\
(=156 / 286)\end{array}$ \\
\hline Type 2 & $\begin{array}{l}11 \% \\
(=6 / 57)\end{array}$ & $\begin{array}{l}32 \% \\
(=9 / 28)\end{array}$ & $\begin{array}{c}70 \% \\
(=19 / 27)\end{array}$ & $\begin{array}{c}34 \% \\
(=11 / 32)\end{array}$ & $\begin{array}{c}\mathbf{3 1 \%} \\
(=45 / 144)\end{array}$ \\
\hline Type 3 & $\begin{array}{c}25 \% \\
(=28 / 110)\end{array}$ & $\begin{array}{c}35 \% \\
(=29 / 84)\end{array}$ & $\begin{array}{c}27 \% \\
(=12 / 45)\end{array}$ & $\begin{array}{c}40 \% \\
(=17 / 42)\end{array}$ & $\begin{array}{c}\mathbf{3 1 \%} \\
(=86 / 281)\end{array}$ \\
\hline Type 4 & $\begin{array}{l}34 \% \\
(=3 / 76)\end{array}$ & $\begin{array}{l}17 \% \\
(=8 / 48)\end{array}$ & $\begin{array}{l}15 \% \\
(=8 / 52)\end{array}$ & $\begin{array}{l}10 \% \\
(=4 / 38)\end{array}$ & $\begin{array}{c}11 \% \\
(=23 / 214)\end{array}$ \\
\hline Total & $\begin{array}{c}17 \% \\
(=49 / 282)\end{array}$ & $\begin{array}{c}35 \% \\
(=83 / 235)\end{array}$ & $\begin{array}{c}45 \% \\
(=97 / 217)\end{array}$ & $\begin{array}{c}42 \% \\
(=81 / 191)\end{array}$ & $\begin{array}{c}\mathbf{3 4 \%} \\
(=310 / 925)\end{array}$ \\
\hline
\end{tabular}

Table 5: Strategic resolution of dilemmas (Perfect anticipations assumption), by order of election in a sequence (4-election sessions)

For example, one can read that we oberved in our data 286 dilemmas of type 1, 156 of which are resolved strategically, that is 55\%. Summing over all types (last line of the top part of the table), we observe in our data 925 dilemmas, $34 \%$ of which are resolve strategically. Table 5 clearly shows how this percentage depends on the type of reasoning: Type 1 dilemmas are often resolved in the strategic manner (55\% of the time) whereas Type 4 dilemmas are not (11\% of strategic resolutions). Types 2 and 3 are similar, and are resolved strategically in $31 \%$ of the cases. These numbers are averages over nine sessions.

It is also interesting to study how these numbers vary with the order of the election in the sequence. Indeed, we expect the percentage of strategic resolution of dilemmas to increase as time goes by. As voters become familiar with the specific political structure and with their own position in the sequence, their ability to reason strategically should increase. Table 5 (columns "Election 1" 
to "Election 4") provides the information. We do observe such an evolution for Type 1 reasoning: the strategic resolution of dilemmas increases from $31 \%$ in the first election up to $62 \%$ in the fourth. We observe only a weak (unclear) evolution for Type 2 and Type 3, and no evolution for Type 4.

We conclude that the strategic model is on average relatively weak in predicting individual behavior in cases of conflict with the sincere recommendation: the strategic recommendation is followed in only $34 \%$ of such cases. But this performance varies with the type of reasoning involved, Type 1 being more often followed than the other types, and Type 4 being seldom followed. For the type which is the most often followed (Type 1), the success of the strategic model increases substantially with the order of the election within the sequence.

Influence of the experiment location. The place where the experiment was done is either Paris or Montreal. Subjects in Montreal live in a country where the standard rule is First Past The Post, and may not be used to reasoning about run-off elections. Subjects in Paris live in a country where Two-round run-off is the standard voting rule and backward reasoning with respect to a run-off is commonly discussed. Table 6 shows how dilemmas are resolved in each location.

\begin{tabular}{|l|c|c|c|}
\hline & Paris & Montreal & $\begin{array}{c}\text { Total } \\
\text { Type 1 }\end{array}$ \\
$\begin{array}{c}48 \% \\
(=81 / 169)\end{array}$ & $\begin{array}{c}64 \% \\
(=75 / 117)\end{array}$ & $\begin{array}{c}55 \% \\
(=156 / 286)\end{array}$ \\
\hline Type 2 & $\begin{array}{c}38 \% \\
(=25 / 65)\end{array}$ & $\begin{array}{c}25 \% \\
(=20 / 79)\end{array}$ & $\begin{array}{c}31 \% \\
(=45 / 144)\end{array}$ \\
\hline Type 3 & $\begin{array}{c}31 \% \\
(=57 / 185)\end{array}$ & $\begin{array}{c}30 \% \\
(=29 / 96)\end{array}$ & $\begin{array}{c}31 \% \\
(=86 / 281)\end{array}$ \\
\hline Type 4 & $\begin{array}{c}8 \% \\
(=13 / 154)\end{array}$ & $\begin{array}{c}17 \% \\
(=10 / 60)\end{array}$ & $\begin{array}{c}11 \% \\
(=23 / 214)\end{array}$ \\
\hline Total & $\begin{array}{c}31 \% \\
(=176 / 573)\end{array}$ & $\begin{array}{c}38 \% \\
(=134 / 352)\end{array}$ & $\begin{array}{c}34 \% \\
(=310 / 925)\end{array}$ \\
\hline
\end{tabular}


Table 6: Strategic resolution of dilemmas (Perfect anticipations assumption), by experiment location (4-election sessions)

It seems that subjects in Canada are more successful in performing Type 1 reasoning (64\% of strategic resolution) than French subjects (48\%), and that the reverse is true for Type 2 reasoning (38\% of strategic resolution for French subjects vs. 25\% for subjects in Canada). This is consistent with the observation that Type 1 reasoning is close to strategic reasoning FPTP elections with no run-off (vote for the leading candidate if you like him better than his main challenger). But, contrary to what could be expected along these lines, subjects in Canada seem more likely to perform Type 4 reasoning (17\% of strategic resolution) than subjects in France (only $8 \%$ of strategic resolution).

Influence of the political structure. In this analysis, we pooled, at the session level, observations colected under the different political structures. Note that our objective was not to compare outcomes under the different structures, but to use these different profiles in order to generate the various types of reasoning that had been identified by the theory. Since no single profile could generate all the types, we had to use various profiles. Now, one may still wonder whether the propensity to strategically resolve dilemmas, which is our main variable of interest, depends on the profile structure. To answer this question, Table 7 shows the result of a probit regression, with the propensity to strategically resolve dilemmas as the dependent variable, and the types and the structures are independent variables. We also control for the fact that people may be less prone to cast a strategic vote when this entails supporting a candidate that is far away from one's position. To that effect, we created a 'distance sincerity' variable that equals the distance between the positions of the sincere choice and strategic choice candidates. We expect a negative 
coefficient: the greater the distance, the greater the resistance to follow the strategic recommendation.

\begin{tabular}{|c|c|c|c|c|}
\hline Variable & $\mathbf{d F} / \mathbf{d x}$ & Std. Err. & $\mathbf{z}$ & $\mathbf{P}>\mathbf{z}$ \\
\hline Type 1 & $.1773597 * * *$ & .0549679 & 3.30 & 0.001 \\
\hline Type 3 & -.0145678 & .0482702 & -0.30 & 0.764 \\
\hline Type 4 & $-.1548862^{* * *}$ & .0514211 & -2.72 & 0.007 \\
\hline Structure sII & .046037 & .0361833 & 1.28 & 0.202 \\
\hline Structure 5 cand. & .023702 & .0334415 & 0.71 & 0.481 \\
\hline Distance sincerity & $-.0304623^{* * * *}$ & .006148 & -4.89 & 0.000 \\
\hline Observed P & .3351351 & & & \\
\hline Predicted P (at & .3049573 & & & \\
\hline x-bar) & & & & \\
\hline Pseudo R2 & 0.1238 & & & \\
\hline Nb of observations & 925 & & & \\
\hline
\end{tabular}

Note: Probit regression, reporting marginal effects. $\mathrm{dF} / \mathrm{dx}$ is for discrete change of dummy variable from 0 to $1 ; \mathrm{z}$ and $\mathrm{P}>|\mathrm{z}|$ correspond to the test of the underlying coefficient being 0 .

Table 7: Determinants of the propensity to resolve strategically a dilemma

Table 7 confirms that Type 1 (resp. Type 4) is more often (resp. less often) followed that Type 2 (the reference category), and that there is no statistical difference between Type 2 and Type 3. There is no difference between structure sII and structure sI nor between the three or the five candidate contexts. Finally, as predicted, the larger the distance between the sincere and the strategic choices, the weaker the propensity to vote strategically. 


\section{Additional analyses: myopic anticipations and longer sequences}

\subsection{The myopic anticipations assumption}

So far, we have assumed that voters' anticipations about the scores of the candidates in the next election are noisy, but correct in expectation. In this section, we replicate our analyses under an alternative assumption about how subjects form beliefs about first-round scores. We assume in this section that each voter forms her beliefs about how other voters will behave in the current election based on the results of the previous election, and thinks that other voters will behave in the current election just as they did in the previous election. As in the perfect anticipations model, we assume that these beliefs are noisy: when anticipating the outcomes of the current election, voter $i$ believes that with the (high) probability $1-\varepsilon$, voter $j$ will vote today as she voted in the previous election, but that with a small error probability $\varepsilon$, voter $j$ will vote for another, randomly chosen candidate. Errors are assumed to be independent across voters, and independent across elections. Regarding the anticipations about run-offs, we assume that there are identical to those under the perfect anticipations model

Note that the "myopic" theory only makes prediction for the second, third, and fourth elections in each sequence. It does not predict how voters behave before they observe any results.

In our analyses, we run these computations for each individual at each election. As in the perfect anticipations model, we confine ourselves to three mistakes or less.

Table 8, which describes the performance of the strategic model depending on the type of reasoning and the order of the election in the sequence, shows very similar results to those obtained under the perfect anticipations assumptions (see Table 5): Type 1 dilemmas are often resolved in the strategic manner (59\% of the time) whereas Type 4 dilemmas are not $(15 \%$ of strategic resolutions). 


\begin{tabular}{|c|c|c|c|c|c|c|}
\hline \multicolumn{6}{|c|}{ Myopic anticipations assumption } & \multirow{2}{*}{$\begin{array}{c}\text { Perfect } \\
\text { Elections 2- } 4\end{array}$} \\
\hline & Election 1 & Elections 2 & Election 3 & Election 4 & Total & \\
\hline Type 1 & / & $\begin{array}{c}46 \% \\
(=18 / 39)\end{array}$ & $\begin{array}{c}60 \% \\
(=45 / 75)\end{array}$ & $\begin{array}{c}65 \% \\
(=60 / 93)\end{array}$ & $\begin{array}{c}\mathbf{5 9 \%} \\
(=123 / 207)\end{array}$ & $\begin{array}{c}58 \% \\
(=123 / 207)\end{array}$ \\
\hline Type 2 & I & $\begin{array}{c}28 \% \\
(=16 / 57)\end{array}$ & $\begin{array}{c}54 \% \\
(=15 / 28)\end{array}$ & $\begin{array}{c}48 \% \\
(=13 / 27)\end{array}$ & $\begin{array}{c}39 \% \\
(=44 / 112)\end{array}$ & $\begin{array}{c}45 \% \\
(=39 / 87)\end{array}$ \\
\hline Type 3 & / & $\begin{array}{c}45 \% \\
(=49 / 110)\end{array}$ & $\begin{array}{c}43 \% \\
(=36 / 84)\end{array}$ & $\begin{array}{c}36 \% \\
(=16 / 45)\end{array}$ & $\begin{array}{c}\mathbf{4 2 \%} \\
(=101 / 239)\end{array}$ & $\begin{array}{c}34 \% \\
(=58 / 171)\end{array}$ \\
\hline Type 4 & / & $\begin{array}{c}14 \% \\
(=11 / 76)\end{array}$ & $\begin{array}{l}17 \% \\
(=8 / 48)\end{array}$ & $\begin{array}{l}13 \% \\
(=7 / 52)\end{array}$ & $\begin{array}{c}15 \% \\
(=26 / 176)\end{array}$ & $\begin{array}{c}14 \% \\
(=20 / 138)\end{array}$ \\
\hline Total & / & $\begin{array}{c}33 \% \\
(=94 / 282)\end{array}$ & $\begin{array}{c}44 \% \\
(=104 / 235)\end{array}$ & $\begin{array}{c}44 \% \\
(=96 / 217)\end{array}$ & $\begin{array}{c}\mathbf{4 0 \%} \\
(=294 / 734)\end{array}$ & $\begin{array}{c}41 \% \\
(=261 / 643)\end{array}$ \\
\hline
\end{tabular}

Table 8: Strategic resolution of dilemmas (Myopic anticipations assumption), by order of election in a sequence (4-election sessions)

It seems, when comparing Tables 5 and 7 that the strategic model performs slightly better under the myopic antipations assumption. Such a comparison is misleading, since the myopic models only generates recommendations starting at the second election. To make the comparison more meaningful, we report in the last column of Table 8 (column "Perfect") the performance of the strategic model under the perfect anticipations assumption when restricting attention to the last three elections in the sequence. We see then that the performances are quite similar.

We infer that our conclusions regarding the voters' propensity to perform the various types of reasoning are robust to the specific assumption we make regarding their anticipations. Of course, we only study here two models of anticipations, but they seem to be two extreme cases, from the most naive (myopic forcasting) to the perfectly sophisticated one (exact forcasting). Studying alternative models of formation of beliefs is beyond the scope of the paper. 


\subsection{More repetitions: a follow-up experiment with longer sequences of elections}

We observed in Table 5 that, at least for Type 1, the performance of the strategic model increases over time. In our baseline experiment, we conducted sequences of four elections each. The question remains whether this performance would improve if subjects take part in longer sequences of elections. In a follow-up experiment, we used a protocol exactly similar to the one used in the baseline experiment, except that we ran sequences of 15 elections under the same candidate profile and the same randomly asigned positions for the subjects. In this follow-up experiment, we had only run-off elections and we ran eight such sessions in Paris.

Table 9 shows, for each type of reasoning, the percentage of dilemmas which are resolved strategically. The numbers shown in Table 9 correspond to those in Table 5 for the baseline experiment.

\begin{tabular}{|c|c|c|c|c|}
\hline & $\begin{array}{c}\text { First } 4 \\
\text { Elections }\end{array}$ & $\begin{array}{l}\text { Middle } 7 \\
\text { Elections }\end{array}$ & $\begin{array}{c}\text { Last } 4 \\
\text { Elections }\end{array}$ & Total \\
\hline Type 1 & $\begin{array}{c}33 \% \\
(=43 / 131)\end{array}$ & $\begin{array}{c}68 \% \\
(=131 / 192)\end{array}$ & $\begin{array}{c}73 \% \\
(=83 / 114)\end{array}$ & $\begin{array}{c}\mathbf{5 8 \%} \\
(=256 / 437)\end{array}$ \\
\hline Type 2 & $\begin{array}{c}29 \% \\
(=34 / 116)\end{array}$ & $\begin{array}{l}48 \% \\
(=23 / 48)\end{array}$ & $\begin{array}{l}45 \% \\
(=18 / 40)\end{array}$ & $\begin{array}{c}\mathbf{3 7 \%} \\
(=75 / 204)\end{array}$ \\
\hline Type 3 & $\begin{array}{c}26 \% \\
(72 / 278)\end{array}$ & $\begin{array}{c}31 \% \\
(=60 / 193)\end{array}$ & $\begin{array}{l}49 \% \\
(=34 / 70)\end{array}$ & $\begin{array}{c}\mathbf{3 1 \%} \\
(=166 / 541)\end{array}$ \\
\hline Type 4 & $\begin{array}{c}6 \% \\
(=12 / 189)\end{array}$ & $\begin{array}{c}7 \% \\
(=12 / 167)\end{array}$ & $\begin{array}{l}17 \% \\
(=5 / 29)\end{array}$ & $\begin{array}{c}\mathbf{8 \%} \\
(=29 / 385)\end{array}$ \\
\hline Total & $\begin{array}{c}23 \% \\
(=164 / 714)\end{array}$ & $\begin{array}{c}38 \% \\
(=228 / 600)\end{array}$ & $\begin{array}{c}55 \% \\
(=138 / 253)\end{array}$ & $\begin{array}{c}\mathbf{3 4 \%} \\
(=526 / 1567)\end{array}$ \\
\hline
\end{tabular}

Table 9: Strategic resolution of dilemmas (Myopic anticipations assumption), by order of election in a sequence (15-election sessions) 
The last column presents the total over the 15 elections. For example, one can read that we oberved a total of 437 Type 1 dilemmas, of which 256 are resolved strategically, that is, $58 \%$. Summing over types (last line of the table), we observe in our data 1,567 dilemmas, of which $34 \%$ are resolved strategically. Note that the results are very close to those observed with the shorter sequence of elections.

Table 9 also provides some information on how the resolution of dilemmas evolves over time (column "First 4 Elections" to column "Last 4 Elections"). As in the shorter sequence, we observe a strong evolution for Type 1 reasoning: the strategic resolution of dilemmas increases from $33 \%$ in the first four elections up to $73 \%$ in the last four elections. Contrary to what was observed for the other types of reasoning in the shorter sessions (weak or unclear evolutions), we observe over a larger number of elections that some learning also takes place for the other types of resaning, although the evolution is much more modest than for Type 1 reasoning. But, even in the last four elections, the performance of the strategic model remains far from perfect in Type 2 and Type 3 situations (between 45 and 50\% of correct predictions) and quite weak in the case of type 4 reasoning: only $17 \%$ of correct predictions.

\section{Conclusion}

The objective of this research has been to deepen our understanding of strategic voting at the individual level in two-round run-off elections.

To that end, we have proposed a precise description of what it means, in theory, for a voter to be rational in such elections and we have put forward a coherent typology of the types of reasoning a voter may have to perform in such elections. 
We then conducted a laboratory experiment designed to test, at the individual level, whether subjects perform or not the strategic reasonings prescribed by the theory. We find that voters tend to vote strategically when the strategic recommendation follows from a simple line of reasoning. In particular, when there is a serious possibility that a candidate reaches the absolute majority threshold in the first round, the same simple reasoning that drives rationality in FPTP elections applies. In that case, a substantial fraction of the subjects cast votes which are consistent with this line of reasoning.

On the other hand the conditional reasonings implied in "backward induction" which are inherent to strategizing in multi-stage procedures are much less followed by voters, despite the fact that the run-off game has only two steps. The experimental literature has noticed that backward induction on many steps, even if each step is straightforward, is not well performed by interacting human subjects (Rosenthal 1981, McKelvey and Palfrey 1992). This rises doubts about the empirical relevance of the corresponding game-theoretical concept of iterative elimination of dominated strategies in the context of voting, despite its leverage in the mechanical design literature (Moulin 1979, Bag et al. 2009, Horan 2013).

In their lab voting experiments, Esponda and Vesta 2013 find that between $50 \%$ and 80\% of subjects behave non-strategically, and they note that "mistakes are mainly driven by difficulty in extracting information from hypothetical, rather than actual, events". Backward induction is precisely a case where the required "information" is not present in observable events but has to be deduced from hypothesis. Likewise, Koriyama and Ozkes 2014 try to fit models of cognitive hierarchies to voting situations. The cognitive hierarchy model is another (different) case in which the beliefs of the individual about the others' behavior are based on more and more hypothetical assumptions as one climbs the cognitive hierarchy. The obtained results imply that very few participants in the lab exhibit high level of this kind of sophistication. 
Comparing observation in the laboratory with experiments closer to real elections, Igersheim et al. 2014 found that there is more strategic voting in the lab, with monetary incentives, than out of the lab. Our results therefore tend to explain why both extreme positions according to which voters are either absolutely rational or always sincere are not valid. The contribution of this paper is that there are many simple strategic votes but few sophisticated ones 


\section{References}

Parimal Kanti Bag, Hamid Sabourian and Eyal Winter (2009), "Multi-Stage Voting, Sequential Elimination and Condorcet Consistency", Journal of Economic Theory 144: 1278-1299.

André Blais (2003), "Strategic Voting in the 2002 French Presidential Election" in: The French Voter: Before and After the 2002 Elections, Michael Lewis-Beck (ed.), Hampshire: Palgrave.

André Blais, Martial Foucault, Simon Labbé-Saint Vincent, Jean-François Laslier, Nicolas Sauger, and Karine Van der Straeten (2014) "Measuring perceptions of candidate viability in voting experiments" working paper.

André Blais, Simon Labbé-Saint Vincent, Jean-François Laslier, Nicolas Sauger and Karine Van der Straeten (2010) "Strategic vote choice in one round and two round elections" Political Research Quarterly 20 (10): 1-9.

André Blais, Louis Massicotte and Agnieszka Dobrzynska (1997), "Direct Presidential Elections: A World Summary" Electoral Studies 16: 441-455.

André Blais,Richard Nadeau, Elisabeth Gidengil, and Neil Nevitte (2001) "Measuring strategic voting in multiparty plurality elections" Electoral Studies 20: 343-352.

Laurent Bouton (2013), "A Theory of Strategic Voting in Run-off Elections" American Economic Review 103: 1248-1288.

Laurent Bouton and Gabriele Gratton (2013) “Majority Runoff Elections: Strategic Voting and Duverger's Hypothesis", working paper.

Gary W. Cox (1997), Making Votes Count: Strategic Coordination in the World's Electoral Systems, Cambridge University Press.

Ignacio Esponda and Emmanuel Vespa (2013), Hypothetical Thinking and Information Extraction in the Laboratory. American Economic Journal: Microeconomics, forthcoming

Robert Forstythe, Thomas A. Rietz, Roger B. Myerson, and Robert J. Weber (1993), "An Experiment on Coordination in Multicandidate Elections: the Importance of Polls and Election Histories", Social Choice and Welfare 10: 223-247.

Matt Golder (2005), "Democratic Electoral Systems Around the World, 1946-2000", Electoral Studies 24: 103-121. 
Thomas Gschwend (2007a), "Ticket-Splitting and Strategic Voting under Mixed Electoral Rules: Evidence from Germany", European Journal of Political Research 46: 1-23.

Thomas Gschwend (2007b),"Institutional Incentives for Strategic Voting and Party System Change in Portugal." Portuguese Journal of Social Science 6: 15-31.

Sean Horan (2013), "Implementation of Majority Voting Rules", UQAM working paper.

Herrade Igersheim, Antoinette Baujard, Frédéric Gavrel, Jean-François Laslier, and Isabelle Lebon (2014) "Individual Behavior under Evaluative Voting. A comparison between laboratory and In Situ experiments" working paper.

Jeffrey Karp, Jack Vowles, Susan Banducci and Todd Donovan (2002), "Strategic Voting, Party Activity, and Candidate Effects: Testing Explanations for Split Voting in New Zealand's New Mixed System", Electoral Studies 21: 1-22.

Kei Kawai and Yasutora Watanabe (2012), "Inferring Strategic Voting” American Economic Review, 103, 624-62.

Yukio Koriyama and Ali-Ishan Ozkes (2014), "The Condorcet jury theorem under cognitive hierarchies: theory and experiments” working paper, Ecole Polytechnique, Paris..

Sebastian Kube and Clemens Puppe (2009), "(When and how) do voters try to manipulate? Experimental evidence from Borda elections", Public Choice 139: 39-52.

Igniacio Lago (2008) "Rational Expectations or Heuristics?: Strategic Voting in Proportional Representation Systems" Party Politics 14: 31-49.

Jean-François Laslier (2009) "The Leader rule: a model of strategic approval voting in a large electorate" Journal of Theoretical Politics 21: 113-136.

Cesar Martinelli (2002), Simple Plurality Versus Plurality Runoff with Privately Informed Voters, Social Choice and Welfare, 19, 901-19.

Jennifer Merolla and Laura B. Stephenson (2007), "Strategic Voting in Canada: A Cross Time Analysis", Electoral Studies 26: 235-246.

Richard D. McKelvey and Thomas R. Palfrey (1992), "An experimental study of the centipeded game", Econometrica 60: 803-836.

Rebecca Morton and Thomas Rietz (2006). Majority Requirements and Voter Coordination. New 
York University Annual Survey of American Law, 63, 691-726.

Hervé Moulin (1979), "Dominance solvable voting schemes", Econometrica 47: 1337-1351.

Roger B. Myerson (1991), Game theory: analysis of conflict, Harvard University Press, Cambridge.

Roger B. Myerson (2000), "Large Poisson games" Journal of Economic Theory 94: 7-45.

Roger B. Myerson (2002). "Comparison of Scoring Rules in Poisson Voting Games" Journal of Economic Theory 103: 219-251,

Roger B. Myerson and Robert J. Weber (1993), " A theory of voting equilibrium", American Political Science Review 87: 102-114.

Thomas Rietz (2008) “Three-wayIn: The Hand experimental election results: strategic voting, coordinated outcomes and Duverger's law" In: The Handbook of Experimental Economics Results, CR Plott and VL Smith, editors, Elsevier Science, Amsterdam, pp. 889-897.

Robert Rosenthal (1981), "Games of Perfect Information, Predatory Pricing, and the Chain Store" Journal of Economic Theory 25: 92-100.

Reinhard Selten (1975), "Re-examination of the perfectness concept for equilibrium points in extensive games", International Journal of Game Theory 4: 25-55.

Jörg Spenkuch (2014), On the Extent of Strategic Voting, mimeo Northwestern University

Amos Tversky (1972), “Choice by elimination” Journal of Mathematical Psychology 9: 341-367.

Amos Tversky and Shmuel Sattah (1979), "Preference trees" Psychological Review 86: 542-573.

Karine Van der Straeten, Jean-François Laslier, Nicolas Sauger and André Blais (2010), "Strategic, sincere, and heuristic voting under four election rules: an experimental study", Social Choice and Welfare 35: 435-472 


\section{Appendix: The choice of candidate positions ("political supply structures") in the}

\section{experiment}

We explain here the precise choice of the positions of the candidates in the experiment. We have identified, in theory, four possible types of strategic reasoning. Our objective in the experiment is to check whether the subjects follow each of them. We therefore aim at designing political structures that are likely to generate all these possible types of reasoning. Because it was difficult to do so with one single profile of candidate positions, we chose to have four different candidate profiles: two under structure sI - one with three and one with five candidates, and two under structure sII - again, one with three and one with five candidates. We explain below which types of reasoning are expected to arise under the various political structures.

Structure sI with positions $(1,4,11,13,20)$. Our typology in part rests on the candidates' relative strength in case of a run-off. Let us therefore start by describing these relative strenghs.

Relative run-off strength of the candidates. Notice that the candidate in position 11 is a Condorcet winner: he gets at least 11 votes (the absolute majority) whoever his opponent, and is therefore bound to defeat any opponent in a run-off. ${ }^{19}$ Consider now the case of the candidate in position 4: he is defeated by the candidates in positions 11 and 13 in case of a run-off, by about the same vote margin. Thus candidates in position 11 and 13 are equally strong when opposed to the

\footnotetext{
${ }^{19}$ Remember that in a run-off with two candidates, voting for the candidate closest to her position is a dominant strategy for the voter. We will assume that voters anticipate other voters to follow such a strategy, possibly with some small unbiased mistakes. The run-off outcomes described here are derived under this assumption. The details of our assumptions about how voters form beliefs about run-off outcomes, and more generally about other voters' behavior, are provided in subsection 3.2.
} 
candidate in position 4. Consider now the candidate in position 13: he looses the run-off against the Condorcet winner, but wins against the candidate in position 4 . The extreme candidates are defeated by all candidates, except possibly by the other extreme candidate. Based on this analysis of the candidates' relative strength in case of run-offs (section 2), we will use the following terminology to describe the candidates: the candidate in position 11 will be called the centrist candidate, candidate in position 13 the strong moderate, and candidate in position 4 the weak moderate.

Types of reasoning. What type of reasoning are voters likely to be required to perform when facing such a political structure? To get a flavor of what can be induced by this type of political supply, imagine that all voters start by voting sincerely for the candidates closest to them.

Consider first the profile with three candidates. The centrist candidate gets votes from voters in position 8 to 11 or 12 , that is about 4.5 votes. His opponents in position 4 and 13 should respectively get about 8 and 8.5 votes and thus both would be in the run-off. In the run-off, the strong moderate candidate (position 13) should win in front of his more extreme opponent (position 4). Then some voters who prefer the weak moderate to the strong moderate may desert the centrist candidate in order to try and provoke a first-round victory of the weak moderate (Type 1 reasoning). If the weak moderate appears to be leading (again, the precise assumptions we make about how voters form their anticipations are described in detail in subsection 3.2), and if voters believe that the most likely event is that they are going to be decisive in determining who, between the centrist and the strong moderate, is going to be part of the run-off, then, Type 2 reasoning should be performed, since as noted above, both candidates are equally strong against the weak moderate. If now the strong moderate appears to be leading, and if voters believe that the most likely event is that they are going to be decisive in determining who, between the centrist and the weak moderate, is going to be part of the run-off, then, the choice is really between the centrist 
candidate and the strong moderate. Voters who prefer the centrist candidate to the strong moderate should vote for the centrist candidate (Type 3 reasoning), whereas some right-wing voters should vote for the weak candidate whom they dislike but who would secure a victory of their favorite candidate (Type 4 reasoning). All types of reasoning are thus possible under this structure.

What happens with five candidates? Again, imagine that all voters start by voting sincerely. The centrist candidate still gets 4.5 votes. His moderate opponents now share their votes with the extreme candidates. The weak moderate gets 5 votes, and his extreme neighbor 3 , whereas the strong moderate gets 4.5 votes, and his extreme neighbor 4 . First round winners become much less likely, thus Type 1 reasoning is less likely. The vote difference between the two moderate candidates and the centrist being small, we expect to see Type 2, 3 and 4 reasonings.

Structure sII with positions $(\mathbf{0 , 3 , 8 , 1 5 , 2 0 )}$. In terms of relative run-off strength of the candidates, one may check that a pattern similar to that described in structure sI is observed here. We will therefore use the same terminology to describe the candidates: the candidate in position 8 will be called the centrist candidate, the candidate in position 15 the strong moderate (who loses against the centrist but wins in case of a run-off against the candidate in position 3 ), and the candidate in position 3 the weak moderate.

Let us now describe the types of strategic reasoning which might emerge with such a structure. Let us start with the three-candidate profile. Again, imagine that all voters start by voting sincerely for the candidate closest to them. The centrist candidate, in position 8 , gets votes from voters 6 to 11, that is 6 votes. The strong and weak moderate opponents respectively get 9 and 6 votes. In that case it is clear that the strong moderate will be in a run-off or win in the first round. If the strong moderate is in position to win in the first round, this calls for Type 1 reasoning. If not, in case a run-off is the most likely outcome, voters are pivotal in deciding whom, between the centrist 
and the weak moderate, is going to be part of the run-off. This is a typical situation that calls for reasonings of Type 3 and 4 (since the weak moderate and the centrist candidate are of unequal strength, when facing the strong moderate candidate). With such a structure, we expect to put voters in situations calling for reasonings of Type 1,3 and 4.

What happens with five candidates? Again, imagine that all voters start by voting sincerely. The centrist candidate still gets 6 votes. The weak moderate gets 4 votes, and his extreme neighbor 2 , whereas the strong moderate gets 6 votes, and his extreme neighbor 3 . First round wins become much less likely, thus Type 1 reasonings are less likely. The vote difference between the two moderate and the centrist are small, so we expect to see situations withType 2, 3 and 4 reasonings.

Conclusion about the candidate profiles. All types of reasonings can be generated by both political structures, but in different proportions: Type 1 is more likely in structure sII, Type 2 is more likely in structure sI, and Type 3 and 4 should be present under both structures. Furthermore, Type 1 situations are more likely to occur with three candidates than with five candidates. 